\title{
Fast track surgery for biliodigestive derivation: Initial experience
}

\section{Daniel Rios-Cruz, Joaquin Valerio-Ureña, Julio Abraham Hernández- Ascencio, Patricia Galindo-López, Veronica Torres-Medina}

\begin{abstract}
Aims: Talk about Fast Track Surgery is referring to a series of measures implemented to accelerate postoperative recovery of the patient. This has been well demonstrated for colorectal surgery with good results. There is very little experience on its application to biliary surgery. The aim of this study is to describe the initial experience of the application of Fast Track Surgery protocol to biliodigestive surgery at high speciality hospital of Veracruz. Methods: Descriptive, transversal, prospective study. Patients undergoing some kind of biliodigestive derivation, from January 2012 to December 2013 in our hospital under the protocol of Fast Track Surgery, were included. Results: 12 patients were treated. Nine underwent Hepp-Couinaud type derivation; three, common bile duct-duodedum anastomosis was performed. No patient remained with probes or drains after surgery. The time to start orally was $7.27 \pm 2.68$ hours; time to start mobilization
\end{abstract}

Daniel Rios-Cruz ${ }^{1}$, Joaquin Valerio-Ureña ${ }^{1}$, Julio Abraham Hernández-Ascencio ${ }^{1}$, Patricia Galindo-López² ${ }^{2}$ Veronica Torres-Medina ${ }^{3}$

Affiliations: ${ }^{1}$ Department of Surgery, High Speciality Hospital of Veracruz. Avenida 20 de noviembre S/N Centro. CP. 91900 Veracruz, Veracruz, México; ${ }^{2}$ School of Medicine University of Veracruz, México; ${ }^{3}$ Department of Anesthesiology, High Speciality Hospital of Veracruz. Avenida 20 de noviembre S/N Centro. CP. 91900 Veracruz, Veracruz, México.

Corresponding Author: Dr. Daniel Rios Cruz, JF Oca \# 43 interior 4 entre Amado Nervo y Hernández y Hernández, Colonia Flores Magón, Veracruz, Veracruz,México, C.P. 91900; Ph: (52) 22978066 11, Fax: (52) 22978066 11; Email: jobzon@hotmail.com

Received: 01 October 204

Accepted: 19 November 2014

Published: 17 March 2015 out of bed was $5.39 \pm 2.50$ hours. Patients were discharged at $73.68 \pm 43.81$ hours post-surgical event. Two patients had surgical site infection. No re-admissions were presented. Conclusion: Application of Fast Track Surgery protocol appears to be safe and feasible. However, it is necessary to expand the sample of patients.

Keywords: Biliary tract, Biliodigestive derivation, Enhanced recovery after surgery, Fast track surgery

\section{How to cite this article}

Rios-Cruz D, Valerio-Ureña J, HernándezAscencio JA, Galindo-López P, Torres-Medina V. Fast track surgery for biliodigestive derivation: Initial experience. Int $\mathrm{J}$ Hepatobiliary Pancreat Dis 2015;5:9-16.

Article ID: 100028IJHPDDC2015

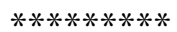

doi:10.5348/ijhpd-2015-28-OA-3

\section{INTRODUCTION}

In the last years the pre, trans and postoperative traditional cares of general surgery have been questioned and even more regarding to gastrointestinal tract [1]. From nutritional support preoperatively to postoperative fasting time through the incision size, if open surgery, have discussed their role in patient recovery.

Traditionally, total fasting of eight hours before sugery, intestinal preparation if resection and anastomosis is programed, big incisions, rest in bed for long periods, were part of a common denominator of patients who underwent gastrointestinal surgery. 
These concepts have been modified in the last decades. Kehlet et al. [2] were the first to establish a specific protocol called Fast-Track; based in the best scientific evidence seeks to minimize the surgical stress response, accelerate recovery, decrease complications and consequently, shorten hospital stay without compromising, therefore, patient safety.

The enhanced recovery programs have been subject of numerous systematic reviews in colorectal surgery and most of them have demonstrated a shortened in hospital stay after surgery, lower rate of complications and decreased hospital costs [3-6]. There are also reports about its use in vascular and urological surgery with good results [7-10]. However, there is a little evidence of its use in hepatobiliary surgery. A recent systematic review suggests that the application of Fast Track Surgery protocol appears to be safe and feasible [11].

In our hospital, we have implemented a enhanced recovery protocol in patients undergoing biliodigestive derivation. The aim of this paper is to present our initial experience with this protocol.

\section{MATERIALS AND METHODS}

All patients who underwent some form of biliodigestive derivation, higher than 18 years, both sexs, under the Fast Track Surgery protocol from January 2012 to December 2013 were included. The protocol consists in to inform the patient what is going to happen during his/her hospital stay, what to expect and what is his/her role in the recovery, allow patient's fluid intake $250 \mathrm{ml}$ up to two hours before the surgical event and, if the patient desired, a water jelly $150 \mathrm{ml}$. During surgery, either foley catheter or nasogastric tube is used if so required, which are removed before patient reversal from anesthesia; at the discretion of the surgical team judicious use of abdominal drains is performed only used if deemed necessary. All anastomoses were performed in a single layer with absorbable stitches 4-o. All the surgeries were performed under general anesthesia and high lumbar regional blockage. The site chosen for the incision is $2 \mathrm{~cm}$ below the right costal margin extending it to two or three inches beyond the left midline by following a hockey stick. Intravenous analgesia starts just finishing to intubate the patient and at the end of surgery is complemented. Then continue oral analgesia with tramadol + paracetamol tablets (325 $\mathrm{mg}$ and 37.5 mg, respectively) every 8 hours starting from two hours after having extubated (after verifying the proper state of consciousness of the patient) and ketorolac $30 \mathrm{mg}$ IV every 6 hours. Taking adequate analgesia, patients are asked to begin mobilizing out of bed as soon as possible, first sitting in a chair and then walking. Once initiated mobilization out of bed, feeding by mouth starts just with liquids which progresses as the patient will tolerate and usually within the first 12 hours after surgery. Patient is discharged having adequate analgesia orally, tolerating diet, walking without presenting a contraindication for hospital discharge as systemic inflammatory response, uncontrolled pain or intolerance to the oral route. The specific protocol is given in Table 1.

Descriptive statistics were used to express the data.

\section{RESULTS}

During the period, 12 patients underwent some form of biliodigestive derivation under the established protocol; 10 women and two men. Age was $41.94 \pm$ 11.89 years. Nine patients underwent Hepp-Couinaud secondary to a biliary tract injury who were referred to our hospital. Three patients underwent common bile ductduodenum anastomosis for palliation of advanced head pancreatic cancer. Surgery time was $5.24 \pm 2.70 \mathrm{hr}$. All patients undergoing Hepp-Couinaud were placed urinary catheter which was removed before patient reversed from anesthesia. Six patients had nasogastric tube placed during surgery to remove the air passing into the gastric chamber during anesthetic induction and was removed before patient was extubated in all cases. By positioning the tube was obtained $10 \mathrm{ml}$ average of residual liquids ingested before surgery. Careful control of hemostasis was performed in all cases. No intra-abdominal drains were used. Respiratory exercises began in the room with the patient awake, this about 4 hours after surgery. The mobilization out of bed was given to $5.39 \pm 2.50 \mathrm{hrs}$ after surgery. The start time of the oral route was presented to $7.27 \pm 2.68 \mathrm{hrs}$ after surgery. Three patients had cholangitis with piobilia documented and of these three, two patients had surgical site infection that was treated with cures. The hospital stay after surgery was $73.68 \pm$ $43.81 \mathrm{hr}$. Being higher in the three patient with biliary tract sepsis and inflammatory response and / or surgical wound infections. No re-admissions occurred during the first 30 days after discharge. During the follow-up 9.04 \pm 6.85 months only one patient died due to pancreatic cancer for which he was carrying; the remaining patients continue under close monitoring at the office without complications due to the surgical procedure (Table 2). Infected wounds were closed in a delayed manner. One of these two patients with severe cholangitis studied by computed tomography showed multiple colangiolares abscesses and one of them was broken and sealed with the diaphragm; pus from biliary tract during surgery was obtained and culture was positive for $E$. coli. This patient had a hospital stay of 8 days after surgery because of the need for close monitoring and the use of intravenous antibiotics.

\section{DISCUSSION}

The protocols of accelerated recovery have come to break paradigms around the perioperative environment of the patient. While it has been documented that general 
Table 1: Fast Track Protocol followed in patients with biliodigestive derivation surgery

\begin{tabular}{|c|c|c|}
\hline $\begin{array}{l}\text { Patient } \\
\text { preparation }\end{array}$ & $\begin{array}{l}\text { Breathing exercises } \\
\text { Preoperative } \\
\text { physical activity }\end{array}$ & $\begin{array}{l}\text { It seeks to the total empathy between patient, family and medical team and is explained } \\
\text { in detail in the protocol that is such that they would be clear. } \\
\text { It teaches the patient how to get out of bed with some help on the day of surgery and } \\
\text { explain the advantages of wandering within hours of surgery; Will be explains to the } \\
\text { patient the importance of not be afraid to breathe deeply despite the surgery being } \\
\text { performed and is taught to the familiar as an adjunct in pulmonary physiotherapy for } \\
\text { the patient. They are emphasizing the importance of nutrition as fast as possible and } \\
\text { avoid prolonged preoperative fasting especially because they are patients with previous } \\
\text { iatrogenic lesions or cancer that already if they have been depleted. } \\
15 \text { repetitions every } 3 \text { hrs. respecting nocturnal sleep, with respiratory exerciser or at } \\
\text { least blow party balloons for previous inhales } 48 \mathrm{hr} \text { before surgery. } \\
\text { Frequent ambulation before surgery and exercises muscle tone of arms and legs is } \\
\text { encouraged. }\end{array}$ \\
\hline $\begin{array}{l}\text { Preoperative oral } \\
\text { route }\end{array}$ & $\begin{array}{l}\text { Normal diet to } \\
8 \text { hrs. previous; } \\
\text { water free demand } \\
\text { until } 3 \text { hours before } \\
\text { surgery. }\end{array}$ & $\begin{array}{l}2 \text { to } 3 \text { hours prior to surgery, } 250 \text { cc of fluid in any of the following ways: chamomile } \\
\text { tea, coffee (both sweetened to taste) orange juice or apple and optionally } 1 \text { water jelly } \\
\text { to } 150 \mathrm{cc} \text {, whether oral medication requires up to } 30 \text { min before surgery with } 30 \mathrm{cc} \text { of } \\
\text { water. }\end{array}$ \\
\hline $\begin{array}{l}\text { Preparation of } \\
\text { the digestive tract }\end{array}$ & $\begin{array}{l}\text { Not required in any } \\
\text { case }\end{array}$ & \\
\hline Trichotomy & No required & $\begin{array}{l}\text { Exceptionally only withdraw if clogged villi at the site of the incision just washing the } \\
\text { patient }\end{array}$ \\
\hline Anesthesia & $\begin{array}{l}\text { General balanced }+ \\
\text { Mixed regional } \\
\text { block }+ \\
\text { Preincisional Local } \\
\text { anesthesia }\end{array}$ & $\begin{array}{l}\text { Fentanyl + propofol + sevorane } \\
\text { Heavy Bupivacaine } 5 \% 12 \text { to } 15 \mathrm{mg} \text { at the onset of subarachnoid anesthesia and } \\
\text { ropivacaine } 7.5 \% 2 \mathrm{ml} \text { or } 150 \mathrm{mg} \text { epidural when closing fascia. } \\
\text { Ropivacaine } 7.5 \% \text { diluted in } 40 \text { cc of saline solution to infiltrate incision site and } \\
\text { infiltration of intercostal nerve points } 6^{\circ}, 7^{\circ} \text { and } 8^{\circ}\end{array}$ \\
\hline Analgesia & $\begin{array}{l}\text { Trans-operative } \\
\text { intravenous } \\
\text { Postoperative (oral } \\
\text { and intravenous) }\end{array}$ & $\begin{array}{l}\text { Before impact, ketorolac } 30 \mathrm{mg} \text { intravenous and fentanyl } 3 \mu \mathrm{g} / \mathrm{kg} / \mathrm{hr} \text { and at the end of } \\
\text { surgery is complemented by ketorolac } 30-60 \mathrm{mg} \text { depending on the patient's weight. } \\
\text { Tramadol tablets + paracetamol ( } 37.5 \mathrm{mg} \text { and } 325 \mathrm{mg} \text { respectively) every } 8 \\
\text { hr.Starting from the two hours after having extubated after verifying the proper state } \\
\text { of consciousness of the patient and ketorolac } 30 \mathrm{mg} \text { IV every } 6 \mathrm{hr} \text {. or ketoprofen } 100 \\
\text { mg IV every } 12 \text { hours until the withdrawal of the IV solutions after verifying good pain } \\
\text { control with oral analgesics. Oral analgesia with ibuprofen } 400 \mathrm{mg} \text { every } 8 \mathrm{hrs} \text { replacing } \\
\text { the endovenous. The patient was discharged with oral analgesics mentioned both by } \\
3-5 \text { days as required with interleaved schedules to always have a good analgesic effect } \\
\text { but prevents the patient wakes up during the night to take drugs. }\end{array}$ \\
\hline $\begin{array}{l}\text { Catheters and } \\
\text { probes }\end{array}$ & $\begin{array}{l}\text { Central venous } \\
\text { catheter } \\
\text { Peripheral vascular } \\
\text { Access } \\
\text { Foley } \\
\text { Nasogastric }\end{array}$ & $\begin{array}{l}\text { It is placed only either if is required to apply damaging drugs to the vessels or is a } \\
\text { priority determining central venous pressure. } \\
\text { One or two routes of short and thick venous access with catheters and usually at the } \\
\text { end of surgery the patient leave the operating room with a single vascular access } \\
\text { pathway. } \\
\text { During the transoperative if is expected a surgery more than } 3 \mathrm{hr} \text { and removed at } \\
\text { the end of surgery unless the patient pass to intensive therapy or requires detailed } \\
\text { monitoring of liquids. } \\
\text { It is placed at the beginning of surgery only when the stomach is distended and } \\
\text { removed before the patient emerges from anesthesia. In cases where is placed, is } \\
\text { tapped and the stomach contents aspirated is measured. }\end{array}$ \\
\hline Drains & $\begin{array}{l}\text { Penrose } 3 / 4 \text { or } \\
\text { drenovack } 1 / 4\end{array}$ & $\begin{array}{l}\text { No drains are placed unless the possibility of an anastomotic leak is suspected and } \\
\text { always prefer to redo an anastomosis at the time if it is necessary instead put a drain. } \\
\text { When a drain is placed, a closed one is preferred. }\end{array}$ \\
\hline Postoperative rest & $\begin{array}{l}\text { In bed } \\
\text { In reposet }\end{array}$ & $\begin{array}{l}\text { On leaving the recovery room, starts in semifowler position in hospitalization bed: } \\
\text { passive or active mobilization of limbs inside the bed. } \\
\text { It passes the patient to a reposet or chair, } 8-16 \mathrm{hrs} \text { after surgery unless there is a } \\
\text { contraindication for this. After the first } 4 \text { hours in semifowler positions the patients } \\
\text { begins to repositioning going from sitting up in bed to sitting with feet out of bed and } \\
\text { finally sitting out of bed except to be night time in which case starts the next morning. } \\
\text { We encourage the patient to urinate out of bed and go to the bathroom to evacuate. }\end{array}$ \\
\hline
\end{tabular}




\begin{tabular}{|c|c|c|}
\hline $\begin{array}{l}\text { Post-operative } \\
\text { (POP) } \\
\text { Ambulation }\end{array}$ & $\begin{array}{l}\text { Day o POP } \\
\text { Day } 1 \text { POP } \\
\text { Day } 2 \text { POP }\end{array}$ & $\begin{array}{l}\text { Starts } 4-16 \mathrm{hr} \text { after surgery; Assisted short walks around the bed and near the stall } \\
\text { where it is located. } \\
\text { The day after the surgery, are made in an average of } 3 \text { walks of } 50,100 \text { and } 200 \mathrm{~m} \text { and } \\
\text { go the bathroom to bathe and perform their stools. } \\
\text { The second day at least } 3 \text { walks 200m each. }\end{array}$ \\
\hline Start of oral route & $\begin{array}{l}\text { Medicaments } \\
\text { Water } \\
\text { Food }\end{array}$ & $\begin{array}{l}\text { The oral medication can initiate even } 2 \text { hrs. after waking from anesthesia with } 30-50 \\
\text { ml of water. } \\
\text { Water intake is allowed to tolerance from the first } 6 \text { hrs. of completed the surgery } \\
\text { Clear liquids } 6 \text { hours after surgery. The next day normal diet low in fats is allowed } \\
\text { and empowers the patient to eat only what he/she wants except that the patient is } \\
\text { distended or is vomiting. }\end{array}$ \\
\hline $\begin{array}{l}\text { Respiratory } \\
\text { therapy }\end{array}$ & $\begin{array}{l}\text { Breathing exercises } \\
\text { Pulmonary } \\
\text { percussion }\end{array}$ & $\begin{array}{l}15 \text { repetitions every } 3 \text { hrs. with inspiratory device respecting nocturnal sleep and if } \\
\text { not have this device, at least with balloon inflation with deep breaths before each } \\
\text { insufflation. } \\
\text { Percussions on the back with the palm of the hand provided by the family every } 3 \text { hrs. } \\
\text { during the day, respecting the patient's sleep. }\end{array}$ \\
\hline $\begin{array}{l}\text { Antithrombotic } \\
\text { measures }\end{array}$ & $\begin{array}{l}\text { Pharmacological } \\
\text { Mechanical }\end{array}$ & $\begin{array}{l}\text { Enoxaparin } 40 \text { mg SC every } 24 \text { hrs.From admission except that have altered times and } \\
\text { for } 1 \text { week after surgery if the daily mobility is inadequate. } \\
\text { Graduated compression stockings to upper third of thighs until the patient wanders at } \\
\text { least } 5 \text { times a day or more than } 600 \mathrm{~m} \text { per day for two consecutive days. }\end{array}$ \\
\hline $\begin{array}{l}\text { Bandages and } \\
\text { girdles }\end{array}$ & abdominal & $\begin{array}{l}\text { Are not used. Their use is avoided and we explain to the patient before surgery its } \\
\text { exceptional use. }\end{array}$ \\
\hline Use of stair & & $\begin{array}{l}\text { Use them once the patient goes home as if asleep upstairs, down to the dining room to } \\
\text { eat each time corresponds intake is encouraged. }\end{array}$ \\
\hline
\end{tabular}

Table 2: Specific characteristics of patients

\begin{tabular}{|c|c|c|c|c|c|c|c|c|c|c|c|}
\hline Patient & Gender & Age* & $\begin{array}{l}\text { Urinary } \\
\text { catheter }\end{array}$ & NGT & $\begin{array}{c}\text { Gastric } \\
\text { residual } \\
\text { volume** }\end{array}$ & $\begin{array}{c}\text { Surgery } \\
\text { Performed }\end{array}$ & $\begin{array}{c}\text { Surgical } \\
\text { Time } \ddagger\end{array}$ & $\begin{array}{l}\text { Mobilization } \\
\text { out of bed } \neq\end{array}$ & $\begin{array}{l}\text { Starting } \\
\text { oral route } \\
\quad \neq\end{array}$ & $\begin{array}{c}\text { Follow } \\
\text { up }{ }^{\dagger}\end{array}$ & $\begin{array}{l}\text { HS post } \\
\text { surgery } \neq\end{array}$ \\
\hline 1 & $\mathrm{~F}$ & 28 & Yes & Yes & 8 & Hepp-Couinaud & 7.5 & 4.4 & 6.5 & 12 & 120 \\
\hline 2 & $\mathrm{~F}$ & 35 & Yes & No & - & Hepp-Couinaud & 6.3 & 5.4 & $7 \cdot 3$ & 20 & 72 \\
\hline 3 & $\mathrm{~F}$ & 45 & Yes & No & - & Hepp-Couinaud & 8.3 & 6.3 & 8.5 & 15 & 72 \\
\hline 4 & M & 55 & No & No & - & $\begin{array}{l}\text { Common bile } \\
\text { duct-duodeno }\end{array}$ & 3 & 5 & 7 & 6 & 48 \\
\hline 5 & $\mathrm{~F}$ & 48 & Yes & Yes & 10 & Hepp-Couinaud & 8.3 & 6.4 & 8.2 & 24 & 192 \\
\hline 6 & $\mathrm{~F}$ & 45 & Yes & Yes & 13 & Hepp-Couinaud & 9.4 & 6.7 & 7.1 & 20 & 144 \\
\hline 7 & $\mathrm{~F}$ & 65 & No & No & - & $\begin{array}{l}\text { Common bile } \\
\text { duct-duodeno }\end{array}$ & 2.5 & 3.5 & 5.2 & 4 & 48 \\
\hline 8 & $\mathrm{~F}$ & 40 & Yes & Yes & 8 & Hepp-Couinaud & 10.2 & 13.2 & 15.6 & 8 & 96 \\
\hline 9 & $\mathrm{~F}$ & 63 & No & Yes & 9 & $\begin{array}{l}\text { Common bile } \\
\text { duct-duodeno }\end{array}$ & 2.3 & 3.6 & 5.2 & 5 & 48 \\
\hline 10 & $\mathrm{~F}$ & 38 & Yes & No & - & Hepp-Couinaud & 7.5 & 6.2 & 8.5 & 6 & 72 \\
\hline 11 & $\mathrm{~F}$ & 29 & Yes & Yes & 12 & Hepp-Couinaud & 7.7 & 5.4 & 7 & 18 & 72 \\
\hline 12 & M & 47 & Yes & No & - & Hepp-Couinaud & 8.3 & 6.2 & 8 & 14 & 72 \\
\hline
\end{tabular}

Abbreviations: NGT: Nasogastric tube. HS: Hospital stay. ${ }^{*}$ Quantity expressed in years. ${ }^{* *}$ Quantity expressed in milliliters. $\dagger$ Quantity expressed in months. ₹Quantity expressed in hours.

anesthesia reduces the protective laryngeal reflex and increases the risk of aspiration, has also been shown that subsequent to ingest a volume of $100 \mathrm{ml}$ of solid or liquid food, the stomach only has about $10 \mathrm{ml}$ of liquid material after an hour and about $30 \mathrm{ml}$ of solid material after three hours. For a passive regurgitation and aspiration during anesthesia, some gastric volume must be present and this is estimated to be around $200 \mathrm{ml}$. Preoperative fluid intake has been associated with better well-being, less thirst and dryness of the mouth and lower postoperative anxiety. Allow habitual coffee intake to coffee drinkers in the morning, can even reduce postoperative headache due to caffeine deprivation [12].

Other authors consider that fasting can be reduced safely up to two to three hours before the surgery [13]. 
Soreide et al. have shown that four hours of fasting are sufficient for a complete gastric emptying [14].

After open abdominal surgery, patients who were treated with an infusion of glucose during the night before surgery, presented a reduction in insulin resistance of $50 \%$ compared with patients who fasted the previous night [15]. Why give so much importance to insulin resistance in a patient undergoing any type of surgery? The insulin resistance is an important phenomenon that lasts up to three weeks after uncomplicated open abdominal surgery [16] and the degree of insulin resistance is an independent predictor of in-hospital stay [17].

The main objective of carbohydrate intake before surgery is to produce the change in metabolism that normally takes place when the patient eats breakfast.

Based on the previous, we can say that allowing fluid intake two hours before anesthesia for elective surgery is safe and improves subjective well-being of the patient. Furthermore, oral carbohydrate intake before surgery reduces surgical stress [12].

For this reason we allow our patients the intake of carbohydrate rich drinks or coffee and none of them developed reflux event during tracheal intubation and in patients in which nasogastric tube was used, the average output of such liquids through the same was $10 \mathrm{ml}$.

The principal factors to keep an inpatient after uncomplicated major abdominal surgery is the need for intravenous analgesia (aching), intravenous fluids (persistent bowel dysfunction) and bed rest (lack of mobility of the patient). These factors interact with each other and retard the patient reintegration to normal activities. Part of the protocol of Fast Track Surgery is to combat these factors with the aim of accelerating postoperative recovery of the patient and with it, decrease the time in which he/she can be incorporated into daily life. The fact that the patient has probes and catheters, prevent free movement either by fear of those devices or discomfort they generate. There are studies which show that the routine use of the nasogastric tube is not justified because there are no advantages over its use after intestinal surgery [18]. Studies have shown that the use of drains in the peritoneal cavity after intestinal resection and anastomosis do not reduce the incidence or severity of an anastomotic leak and its complications [19, 20]. Therefore, in patients submitted to surgery on the Fast Track protocol Surgery, abdominal drains are not used routinely [21]. Likewise with the urinary catheter; if the surgery was performed without complications, its permanence may limit early mobility of the patient. All our patients left the operating room without nasogastric tubes, urinary catheters or drains into the abdominal cavity.

The main foundation of early postoperative mobilization of the patient depends on the pain control. A Cochrane review states that the optimal analgesia that allows early mobilization of the postoperative patient is the continuous epidural analgesia or local anesthesia based on opioids [22]. The employment of intravenous opioids does not produce the same effect as epidural analgesia. NSAIDs can provide additional analgesia and the combination of paracetamol and NSAIDs provide superior analgesia. Our patients were managed with epidural analgesia with $150 \mathrm{mg}$ of $7.5 \%$ ropivacaine before reverting to general anesthesia, subsequently administered intravenously a dose of paracetamol and NSAIDs for later change the route of administration to the oral route.

A meta-analysis concludes that there are no advantages to keep a patient fasting after gastrointestinal resection [23]. Early feeding reduces the risk of infection and length of hospital stay. Also, early feeding was not associated with increased risk of distal anastomotic dehiscence feeding site. Therefore, the patient should be encouraged to start orally four hours after the surgical event. Bed rest only increases insulin resistance and the loss of muscle mass but decreases muscle strength, lung function and tissue oxygenation [24]. Therefore, the patient should be moved out of bed at least two hours on the day of surgery and the remaining days six hours until hospital discharge. On the basis of these principles, patients showed adequate analgesia, which allowed early mobilization out of bed and consequently allowed oral intake. Another objective of the program is to reduce hospital stay. Usually, the biliodigestives surgeries are characterized by longer hospital stays for underlying pathology that is mostly a result of biliary injury. The traditional postoperative behavior is based on prolonged fasting due to anastomosis performed under the argument of intestinal healing. Most of our patients were discharged between $48 \mathrm{hr}$ and $72 \mathrm{hr}$ after the surgical event (common bile duct-duodenum and Hepp-Couinaud respectively) but three of our patients, subjected to Hepp-Couinaud, presented sepsis syndrome associated with cholangitis and piobilia and two of them also had surgical site infections a positive culture for E. coli, so, despite having started early mobilization and orally, their hospital stay was prolonged due to the discomfort it caused their infection to the patient. We can not attribute the surgical site infection to the Fast Track Protocol, as these patients had an identified site of infection (bile duct) that caused contamination to the surgical site.

This is one of the first works that seek to implement an accelerated recovery for biliary surgery. An important limitation of our study is the small number of patients that we collect throughout the study period. In our hospital it has been difficult to break traditional paradigms on perioperative care of patients and few surgeons and anesthesiologists who are open to new knowledge and the possibility to change these paradigms and this is reflected in the small sample that we collect. Another limitation of our study is its way of being descriptive. We do not have a control group with which to compare our results and give more validity and this is partly due to this type of surgery is performed mostly by the group of surgeons who carried out the study. It is important to mention, in this protocol, the patient plays an important role in their recovery so it 
is required to be well informed about what will happen before and after the surgical event, this includes their collaboration to get out of bed and start walking the day of surgery has been performed.

\section{CONCLUSION}

In summary the application of Fast Track Surgery protocol appears to be safe and feasible. However, it is necessary to expand the sample of patients.

$* * * * * * * * *$

\section{Author Contributions}

Daniel Rios-Cruz - Conception and design, Acquisition of data, Analysis and interpretation of data, Drafting the article, Critical revision of the article, Final approval of the version to be published

Joaquin Valerio-Ureña - Conception and design, Acquisition of data, Analysis and interpretation of data, Drafting the article, Critical revision of the article, Final approval of the version to be published

Julio Abraham Hernández-Ascencio - Conception and design, Acquisition of data, Drafting the article, Critical revision of the article, Final approval of the version to be published

Patricia Galindo-López - Conception and design, Acquisition of data, Drafting the article, Critical revision of the article, Final approval of the version to be published. Veronica Torres-Medina - Conception and design, Acquisition of data, Drafting the article, Critical revision of the article, Final approval of the version to be published.

\section{Guarantor}

The corresponding author is the guarantor of submission.

\section{Conflict of Interest}

Authors declare no conflict of interest.

\section{Copyright}

(C) 2015 Daniel Rios-Cruz et al. This article is distributed under the terms of Creative Commons Attribution License which permits unrestricted use, distribution and reproduction in any medium provided the original author(s) and original publisher are properly credited. Please see the copyright policy on the journal website for more information.

\section{REFERENCES}

1. Esteban Collazo F, Garcia Alonso M, Sanz Lopez R, et al. Results of applying a fast-track protocol in a colorectal surgery unit: comparative study. Cir Esp 2012 Aug-Sep;90(7):434-9. [Article in Spanish].

2. Kehlet H, Mogensen T. Hospital stay of two days after open sigmoidectomy with a multimodal rehabilitation programme. Br J Surg 1999 Feb;86(2):227-30.
3. Lassen K, Soop M, Nygren J, et al. Consensus review of optimal perioperative care in colorectal surgery: Enhanced Recovery After Surgery (ERAS) Group recommendations. Arch Surg 2009 Oct;144(10):9619 .

4. Stephen AE, Berger DL. Shortened length of stay and hospital cost reduction with implementation of an accelerated clinical care pathway after elective colon resection. Surgery 2003 Mar;133(3):277-82.

5. Adamina M, Kehlet H, Tomlinson GA, Senagore AJ, Delaney CP. Enhanced recovery pathways optimize health outcomes and resource utilization: A metaanalysis of randomized controlled trials in colorectal surgery. Surgery 2011 Jun;149(6):830-40.

6. Spanjersberg WR, Reurings J, Keus F, Van Laarhoven CJ. Fast Track Surgery versus conventional recovery strategies for colorectal surgery. Cochrane Database Syst Rev 2011 Feb 16;(2):CDoo7635.

7. Huber TS, Carlton LM, Harward TR, et al. Impact of clinical pathway for elective infrarrenal aortic reconstructions. Ann Surg 1998 May;227(5):691-9.

8. Niino $\mathrm{T}$, Hata $\mathrm{M}$, Sezai A, et al. Optimal clinical pathway for the patient with type B cute aortic dissection. Circ J 2009 Feb;73(2):264-8.

9. Koch MO, Smith JAJr. Influence of patient age and comorbidity on outcome of a collaborative care pathway after radical prostatectomy and cystoprostatectomy. J Urol 1996 May;155(5):1681-4.

10. Leibman BD, Dillioglugil O, Abbas F, Tanli S, Kattan MW, Scardino PT. Impact of a clinical pathway for radical retropubic prostatectomy. Urology 1998 Jul;52(1):94-9.

11. Hall TC, Denninson AR, Bilku DK, Metcalfe MS, Garcea G. Enhanced recovery programmes in hepatobiliary and pancreatic surgery: A systematic review. Ann R Coll Surg Engl 2012 Jul;94(5):318-26.

12. Ljungqvist $\mathrm{O}$, Soreide E. Preoperative fasting. Br J Surg 2003 Apr;90(4):400-6.

13. Miller M, Wishart HY, Nimmo WS. Gastric content at induction of anesthesia. Is a 4-hour fast necessary? $\mathrm{Br}$ J Anaesth 1983 Dec;55(12):1185-8.

14. Soreide E, Hausken T, Soreide JA, Steen PA. Gastric emptying of a light hospital breakfast. A study using real time ultrasonography. Acta Anaesthesiol Scand 1996 May;40(5):549-3.

15. Ljungqvist $\mathrm{O}$, Thorell A, Guntiak M, Haggmark T, Efendic S. Glucose infusion instead of preoperative fasting reduces postoperative insulin resistance. J Am Coll Surg 1994 Apr;178(4):329-6.

16. Thorell A, Efendic S, Gutniak M, Häggmark T, Ljungqvist O. Insulin resistance after abdominal surgery. Br J Surg 1994 Jan;81(1):59-63.

17. Thorell A, Nygren J, Ljungqvist O. Insuline resistance: A marker of surgical stress. Curr Opin Clin Nutr Metab Care 1999 Jan;2(1):69-78.

18. Cheatham ML, Chapman WC, Key SP, Sawyers JL. A meta-analysis of selective versus routine nasogastric decompression after elective laparotomy. Ann Surg 1995 May;221(5):469-76.

19. Urbach DR, Kennedy ED, Cohen MM. Colon and rectal anastomoses do not require routine drainage: A systematic review and meta-analysis. Ann Surg 1999 Feb;229(2):174-80. 
20. Jesus EC, Karliczek A, Matos D, Castro AA, Atallah AN. Prophylactic anastomotic drainage for colorectal surgery. Cochrane Database Syst Rev 2004 Oct 18;(4):CDoo210o.

21. Fearon KC, Ljungqvist $\mathrm{O}$, Von Meyenfeldt $\mathrm{M}$, et al. Enhanced recovery after surgery: A consensus review of clinical care for patients undergoing colonic resection. Clin Nutr 2005 Jun;24(3):466-77.

22. Jorgense $\mathrm{H}$, Wetterslev J, Moiniche S, Dahl JB. Epidural local anaesthetics versus opioid-based analgesic regimens on postoperative gastrointestinal paralysis, PONV and pain after abdominal surgery. Cochrane Database Syst Rev 2000;(4):CDoo1893.

23. Lewis SJ, Egger M, Sylvester PA, Thomas S. Early enteral feeding versus "nyl by mouth" after gastrointestinal surgery: Systematic review and meta-analysis of controlled trials. BMJ 2001 Oct 6;323(7316):773-6.

24. Kehlet H, Wilmore DW. Multimodal strategies to improve surgical outcome. Am J Surg 2002 Jun;183(6):630-41.

\section{ABOUT THE AUTHORS}

Article citation: Rios-Cruz D, Valerio-Ureña J, Hernández-Ascencio JA, Galindo-López P, Torres-Medina V. Fast track surgery for biliodigestive derivation: Initial experience. Int J Hepatobiliary Pancreat Dis 2015;5:9-16.

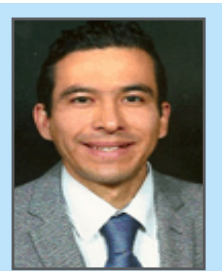

Daniel Rios Cruz is Surgeon at Hospital de Alta Especialidad de Veracruz. He earned undergraduate degree of General Medicine from Facultad de Medicina de la Universidad Autonoma de Yucatán, México and postgraduate degree as General Surgeon from Universidad Veracruzana in Veracruz, Veracruz, Mexico. He has a high speciality course in bariatric surgery and laparoscopic gastrointestinal advanced surgery. He has published many research papers in national and international academic journals and authored an electronic book "Topicos selectos de gastroenterologia" wich will be available very soon. His research interests include obesity surgery, hepatopancreatobiliary surgery and fast track surgery. E-mail: jobzon@hotmail.com

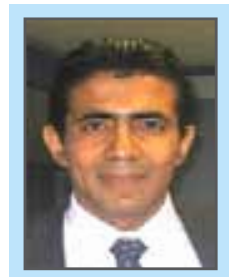

Joaquin Valerio Ureña is Chief of the division of surgery at Hospital de Alta Especialidad de Veracruz in Mexico. He earned undergraduate degree General Medicine from Universidad Veracruzana and postgraduate degree from General Surgeon from Centro Medico Nacional Siglo XXI del IMSS. He has a highly specialized course in gastrointestinal endoscopy and digestive physiology and motility at Instituto Nacional de Nutricion y Ciencias Médicas Salvador Zubiran in Mexico. He has published many research papers in national and international academic journals and authored chapters in books. His search interests include fast track sugery, gastrointestinal physiology and hepatopancreatobiliary surgery. E-mail: drjvalerio@hotmail.com

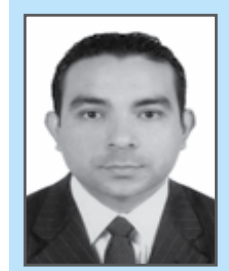

Julio Abraham Hernández Ascencio is General Surgeon at Hospital General de Boca del Rio Veracruz, México. He earned undergraduate degree Medico General from Facultad de Medicina de la Universidad Autónoma de Yucatán en Mérida, Yucatán, México and postgraduate degree form Cirujano General from Hospital de Alta Especialidad de Veracruz; Universidad Veracruzana. Veracruz, Veracruz, México. His research interests include gastrointestinal surgery.

E-mail: jahascencio@hotmail.com

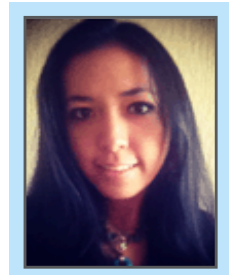

Dra. Patricia Galindo López is a medicine student at Facultad de Medicina, Universidad Veracruzana. Her research interest includes gastrointestinal physiology.

E-mail: pattygalindo91@hotmail.com

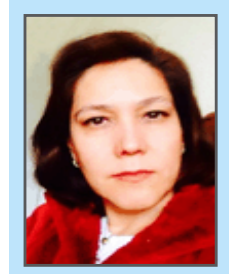

Dra Veronica Torres Medina is Anesthesiologist at highly specialized hospital of Veracruz. She studied General Medicine at Universidad Michoacana de San Nicolas de Hidalgo. Morelia, Michoacan, México and Specialty in Anesthesiology in Hospital de Especialidades del Centro Médico Nacional SIGLO XXI, IMSS, México.

E-mail: verotom272@yahoo.com.mx 
Access full text article on other devices

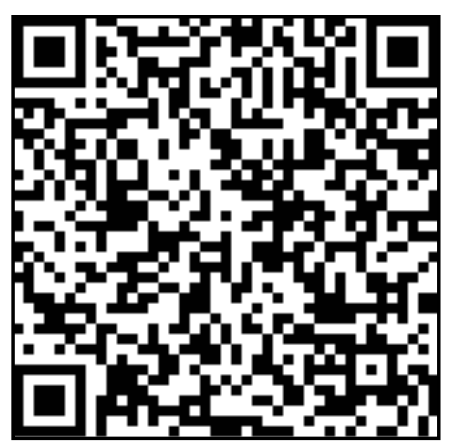

Access PDF of article on other devices

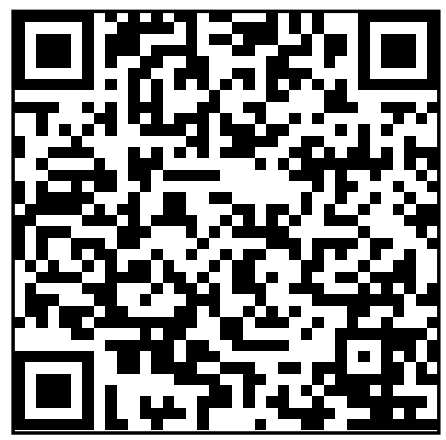

